\title{
PENINGKATAN AKTIVITAS DAN HASIL BELAJAR SISWA MELALUI PENERAPAN MODEL PROBLEM BASED LEARNING DALAM PEMBELAJARAN FISIKA DI KELAS XI MIPA1 SMA NEGERI 12 PEKANBARU
}

\author{
Desta Velly \\ SMA Negeri 12 Pekanbaru \\ e-mail: desta_velly@yahoo.com
}

\begin{abstract}
Abstrak
Hasil tes belajar siswa kelas XI MIPA1 SMA Negeri 12 Pekanbaru pada materi fisika, menunjukkan hampir lebih dari setengah siswa belum mampu menyelesaikan soal-soal dengan baik, maka diperlukan perbaikan atau inovasi pembelajaran. Problem Based Learning adalah salah satu model pembelajaran yang direkomendasikan dalam implementasi kurikulum 2013 karena model ini terbukti mampu menstimulasi kemampuan berfikir tingkat tinggi dengan perancangan masalah dalam konteks nyata. Tujuan dari penelitian tindakan ini adalah untuk meningkatkan hasil belajar dan aktivitas siswa dalam penerapan model Problem Based Learning pada pembelajaran Fisika. Subjek penelitian adalah siswa kelas XI MIPA1, SMA Negeri 12 Pekanbaru. Penelitian ini merupakan penelitian tindakan kelas yang dilakukan dalam 2 siklus. Hasil penelitian ini diperoleh data tes hasil belajar siswa siklus I dengan daya serap sebesar 59,0 \%, pada siklus II daya serap sebesar 69,3\%, aktivitas siswa pada pembelajaran siklus I dan siklus II kategori aktif. Oleh karena itu, penerapan Problem Based Learning dapat meningkatkan aktivitas dan hasil belajar fiska bagi siswa kelas XI MIPA1, SMA Negeri 12 Pekanbaru..
\end{abstract}

Kata kunci : aktivitas belajar, hasil belajar fisika, Problem Based Learning

\begin{abstract}
The results of the students' test of class XI MIPA1 SMA Negeri 12 Pekanbaru on the material of physics, shows that almost more than half of students have not been able to solve the problems well, it needs improvement or. Problem Based Learning is one of the recommended learning models in the implementation of the curriculum 2013 because this model is proven capable of stimulating high-level thinking ability with problem design in real context. The purpose of this action research is to improve learning outcomes and student activities in the application of Problem Based Learning model in Physics learning. The subject of this research is the students of class XI MIPA 1, SMA Negeri 12 Pekanbaru. This research is a classroom action research conducted in 2 cycles. The results of this study obtained data from the test results learners cycle I with absorption of $59.0 \%$, the cycle II absorption of $69.3 \%$, student activity on learning cycle I and cycle II active categories. Therefore, the implementation of Problem Based Learning can improvement the activity and learning outcome of physics learning for students of class XI MIPA1, SMA Negeri 12 Pekanbaru.
\end{abstract}

Keywords : learning activities, physics learning outcome, Problem Based Learning. 


\section{Pendahuluan}

Pengetahuan yang diperoleh siswa dalam pembelajaran Fisika di kelas sangatlah terbatas. Kadang-kadang waktu untuk mengerjakan contoh soal lama, karena siswa tidak sungguh-sungguh mengerjakannya. Tantangan saat ini adalah bagaimana membangkitkan aktivitas dari siswa dan motivasi siswa agar meningkat, bahwa fisika merupakan pelajaran yang menyenangkan, sehingga siswa mulai menerima fisika sebagai pelajaran yang menarik dan tidak membosankan.

Pelaksanaan pembelajaran di kelas pada umumnya selama ini diawali dengan penjelasan materi, memberikan contoh soal dan dilanjutkan dengan pemberian tugas. Siswa hanya melakukan mendengar, mencatat dan mengerjakan apa yang diperintahkan. Untuk itu, guru perlu memperluas pengetahuan ini dengan penalaran siswa melalui menemukan sendiri hal-hal baru dalam bentuk pengalaman belajar. Namun pada kenyataannya di lapangan, masih banyak siswa belajar hanya menghafal konsep-konsep, mencatat apa yang diceramahkan guru. Peningkatan kualitas pendidikan yang utama adalah peningkatan pendidiknya yaitu guru. Hal ini sesuai dengan pendapat Munib (2012) bahwa faktor utama keberhasilan pendidikan Indonesia yaitu guru.

Problem based learning adalah salah satu model pembelajaran yang direkomendasikan dalam implementasi kurikulum 2013, karena model ini terbukti mampu menstimulasi kemampuan berfikir tingkat tinggi (high think order) dengan perancangan masalah dalam konteks nyata.

Hasil belajar merupakan bagian terpenting dalam pembelajaran. Nana Sudjana (2009) mendefinisikan hasil belajar siswa pada hakikatnya adalah perubahan tingkah laku sebagai hasil belajar dalam pengertian yang lebih luas mencakup bidang kognitif, afektif, dan psikomotorik.

Tujuan penelitian ini adalah untuk: 1) meningkatkan hasil belajar siswa, 2) mendeskripsikan aktivitas siswa kelas XI MIPA 1 dalam penerapan model Problem Based Learning pada pembelajaran Fisika di SMA Negeri 12 Pekanbaru.

Sardiman (2010) mengatakan bahwa pada prinsipnya belajar adalah berbuat, tidak ada belajar jika tidak ada aktivitas. Itulah sebabnya mengapa aktivitas merupakan prinsip yang sangat penting dalam interaksi belajar mengajar. Hamalik (2009) menyatakan pendidikan modern lebih menitikberatkan pada aktivitas sejati, dimana siswa belajar sambil bekerja. Dengan bekerja mereka memperoleh pengetahuan, pemahaman, dan aspek-aspek tingkah laku lainnya, serta mengembangkan keterampilan yang bermakna untuk hidup bermasyarakat.

Dapat dijelaskan bahwa dalam proses pembelajaran siswa harus terlibat aktif dalam proses pembelajaran. Keterlibatan siswa tidak hanya mancakup aktivitas fisik tetapi juga mental. Begitu juga dalam pembelajaran fisika, hendaknya ada aktivitas berupa interaksi siswa dengan siswa, siswa dengan guru dan interaksi siswa terhadap materi pelajaran.

Rusman (2013) menyebutkan bahwa problem based learning merupakan inovasi dalam pembelajaran, karena dalam PBL kemampuan berfikir siswa betul-betul dioptimalisasikan melalui proses kerja kelompok atau tim yang sistematis, sehingga siswa dapat memberdayakan, mengasah, menguji, dan mengembangkan kemampuan berfikirnya secara berkesinambungan.

Suharto (2014) menyatakan definisi PBL sebagai Pembelajaran berbasis masalah merupakan model pembelajaran yang dirancang agar siswa mendapat pengetahuan penting yang membuat mereka mahir dalam memecahkan masalah dan memiliki model belajar sendiri serta memiliki kecakapan berpartisipasi dalam tim. Tahap-tahap PBL meliputi: orientasi siswa kepada masalah, mengorganisasikan siswa, membimbing penyelidikan individu dan kelompok, mengembangkan dan menyajikan hasil karya, dan menganalisis, serta mengevaluasi proses pemecahan masalah.

\section{Bahan dan Metode}

Penelitian ini dilaksanakan di kelas XI MIPA 1 SMA Negeri 12 Pekanbaru pada semester ganjil Tahun Pelajaran 2016/2017. Penelitian ini menggunakan dua jenis instrumen yaitu instrumen perangkat pembelajaran dan instrument pengumpulan data. Instrumen perangkat pembelajaran terdiri dari silabus, RPP, dan LKPD. Instrumen pengumpulan data terdiri dari Soal tes hasil 
belajar dan lembar observasi aktivitas siswa. Data yang diperoleh melalui pengamatan (data aktivitas) dan data hasil belajar dianalisis secara deskriptif. Menurut Sugiyono (2011) analisis deskriptif adalah menganalisis data dengan cara mendeskripsikan atau menggambarkan hasil data yang telah dikumpulkan sebagaimana adanya tanpa bermaksud membuat kesimpulan yang berlaku untuk umum atau generalisasi, sedangkan data hasil belajar siswa menggunakan sistem nilai rata-rata kelas dari tes hasil belajar siswa setiap siklus.

Penelitian ini merupakan penelitian tindakan kelas (PTK). Tindakan yang dilakukan pada penelitian ini adalah penerapan model pembelajaran Problem Based Learning dalam pembelajaran fisika. Pelaksanaan penelitian tindakan dirancang dalam 2 siklus. Setiap siklus terdapat beberapa kegiatan yaitu perencanaan, pelaksanaan tindakan, pengamatan, dan refleksi. Menurut Suharsimi (2009) bahwa dalam penelitian tindakan kelas dilaksanakan melalui prosedur: perencanaan, pelaksanaan tindakan, pengamatan, dan refleksi.

Pada tahap perencanaan, peneliti mempersiapkan instrumen penelitian yang terdiri dari perangkat pembelajaran dan instrumen pengumpulan data. Perangkat pembelajaran terdiri dari silabus, rencana pelaksanaan pembelajaran (RPP) serta LKPD. Instrumen pengumpulan data terdiri dari lembar pengamatan aktivitas siswa dan lembar soal tes hasil belajar fisika.

Pelaksanaan tindakan merupakan implementasi dari perencanaan kegiatan yang dilakukan oleh peneliti dalam upaya memperbaiki atau meningkatkan mutu pembelajaran. Pelaksanaan tindakan pada siklus I dilakukan dalam proses pembelajaran secara teratur sesuai kegiatan pembelajaran setiap pertemuan pada RPP 1, yaitu memberikan LKPD 1 sampai LKPD 4 dengan menerapkan PBL. Selanjutnya pelaksanaan tindakan siklus II, berdasarkan perencanaan refleksi siklus I dengan menggunakan RPP 2 dan LKPD 1 sampai LKPD 7 dengan pelaksanaan tindakan yang dilakukan sesuai dengan langkah-langkah model pembelajaran PBL.

Pengamatan dilakukan bersamaan dengan pelaksanaan tindakan. Pelaksanaan pengamatan dilakukan oleh observer.
Pengamatan ini dilakukan terhadap aktivitas siswa selama proses pembelajaran berlangsung dalam waktu dan tempat yang sama. Pengamatan bertujuan untuk mengumpulkan data tentang aktivitas siswa selama proses pembelajaran yang akan digunakan sebagai bahan refleksi.

Refleksi dilakukan setelah tindakan berakhir setiap siklus. Pada tahap ini peneliti mengkaji, melihat, dan mempertimbangkan hasil atau dampak dari tindakan pada siklus pertama. Apabila telah diketahui letak keberhasilan dan hambatan dari siklus pertama, peneliti menentukan rancangan untuk siklus kedua. Setelah siklus kedua berakhir, peneliti menyampaikan rencana yang disarankan kepada peneliti lain dengan catatan-catatan yang telah dimiliki. Refleksi ini bertujuan untuk memperbaiki dan mengoptimalkan kembali pelaksanaan tindakan pertemuan selanjutnya.

\section{Hasil dan Pembahasan}

Pelaksanaan tindakan dengan penerapan PBL dan materi pelajaran yang diberikan setiap siklus, selengkapnya dapat dilihat pada Tabel 1.

\section{Pelaksanaan tindakan}

Tindakan yang dilakukan pada penelitian ini adalah penerapan model pembelajaran Problem Based Learning (PBL) dalam pembelajaran fisika. Setiap pertemuan dilaksanakan pembelajaran yang sesuai dengan tahap-tahap PBL yang dimulai dari orientasi siswa kepada masalah terkait materi, mengorganisasikan siswa dalam mengikuti pembelajaran, membimbing penyelidikan individu dan kelompok dalam mediskusikan materi pelajaran, mengembangkan dan menyajikan hasil karya, dan menganalisis serta mengevaluasi proses pemecahan masalah terhadap masalah terkait materi yang dipelajari. Pada akhir siklus dilaksanakan ulangan harian dan refleksi.

\section{Siklus pertama}

Untuk siklus pertama dilakukan sebanyak empat kali pertemuan dan satu kali ulangan harian dengan materi momentum dan impuls. Kegiatan pembelajaran yang telah 
Tabel 1. Materi pelajaran selama penelitian kelas XI MIPA1 SMA Negeri 12 Pekanbaru

\begin{tabular}{|c|c|c|c|c|c|}
\hline Siklus & Pertemuan & Pokok Bahasan & & Sub Pokok Bahasan & $\begin{array}{l}\text { Waktu } \\
\text { (menit) }\end{array}$ \\
\hline \multirow{4}{*}{$\begin{array}{l}\text { Siklus } \\
\text { I }\end{array}$} & 1 & \multirow{4}{*}{$\begin{array}{l}\text { Momentum dan } \\
\text { Impuls }\end{array}$} & - & Momentum & $2 \times 45$ \\
\hline & 2 & & - & Impuls & $2 \times 45$ \\
\hline & 3 & & - & $\begin{array}{l}\text { Hubungan Impuls dan } \\
\text { Perubahan Momentum }\end{array}$ & $2 \times 45$ \\
\hline & 4 & & & $\begin{array}{l}\text { Hukum Kekekalan } \\
\text { Momentum }\end{array}$ & $2 \times 45$ \\
\hline \multirow{7}{*}{$\begin{array}{l}\text { Siklus } \\
\text { II }\end{array}$} & 1 & \multirow{7}{*}{$\begin{array}{c}\text { Dinamika rotasi } \\
\text { dan Keseimbangan } \\
\text { benda tegar }\end{array}$} & - & Momen gaya & $2 \times 45$ \\
\hline & 2 & & $\begin{array}{l}- \\
-\end{array}$ & $\begin{array}{l}\text { Momen Inersia } \\
\text { Hubungan momen gaya } \\
\text { dengan percepatan sudut }\end{array}$ & $2 \times 45$ \\
\hline & 3 & & - & $\begin{array}{l}\text { Dinamika rotasi dan } \\
\text { Hukum kekekalan energi }\end{array}$ & $2 \times 45$ \\
\hline & 4 & & - & Momentum sudut & $2 \times 45$ \\
\hline & 5 & & - & Keseimbangan Partikel & $2 \times 45$ \\
\hline & 6 & & - & Keseimbangan benda tegar & $2 \times 45$ \\
\hline & 7 & & - & Titik berat & $2 \times 45$ \\
\hline
\end{tabular}

dilakukan pada siklus I, di refleksi oleh peneliti bersama observer melalui kegiatan diskusi. Refleksi dilakukan untuk mengkaji apakah tindakan yang telah dilaksanakan sesuai dengan perencanaan, serta untuk melihat kelemahan-kelemahan yang terjadi pada siklus I agar bisa diperbaiki pada siklus berikutnya.

Kesimpulan dari hasil refleksi masih terdapat beberapa aspek dalam proses pembelajaran yang harus diperbaiki, yaitu :

a. Permasalahan yang diberikan harus lebih dekat dengan kehidupan nyata, agar siswa lebih termotivasi.

b. Guru lebih banyak memberikan pertanyaan-pertanyaan yang menantang yang mengarah kepada persiapan pemecahan masalah. c. Mengontrol siswa-siswa yang tidak bekerja dalam kelompoknya.

d. Memberikan contoh yang bervariasi pada saat memberikan penguatan.

Berdasarkan kesimpulan dari refleksi pada siklus I yang masih memiliki banyak kelemahan dan kekurangan seperti yang telah diuraikan, maka peneliti memperbaiki proses pembelajaran pada siklus II.

\section{Siklus kedua}

Kegiatan pembelajaran yang telah dilakukan pada siklus II, direfleksi oleh peneliti bersama observer melalui kegiatan diskusi. Berdasarkan analisis data yang diperoleh dari lembar pengamatan selama menerapkan model pembelajaran Problem Based Learning (PBL) pada siklus kedua terlihat aktivitas siswa sudah semakin baik. 
Pelaksanaan tindakan proses pembelajaran dapat dilihat dari hasil pengamatan di setiap pertemuan. Aktivitas kegiatan mengalami peningkatan pada setiap pertemuan dan sesuai dengan perencanaan.

Kekurangan yang berhasil peneliti atasi pada siklus kedua ini adalah sebagai berikut:

a. Permasalahan yang diberikan sudah berhubungan dengan kehidupan nyata, sehingga siswa sudah termotivasi.

b. Sudah melaksanakan pengawasan pada siswa, sehingga hampir semua siswa bekerja dalam kelompoknya.

c. Memberikan contoh yang lebih bervariasi pada saat memberikan penguatan.

Berdasarkan kesimpulan dari refleksi pada siklus II yang sudah memperbaiki pembelajaran dari siklus I dan sesuai dengan perencanaan, maka peneliti bersama observer sepakat sampai siklus II. Hasil observasi ratarata aktivitas siswa saat kegiatan pembelajaran pada kedua siklus dapat dilihat pada Tabel 2 .

Tabel 2 menunjukkan rata-rata persentase aktivitas siswa pada setiap siklus meningkat yaitu dari 64,5\% menjadi73,6 \% dengan kategori aktif. Hal ini berarti penerapan model Problem Based Learning (PBL) selama proses pembelajaran dapat membangkitkan keaktifan siswa. Sesuai dengan hasil penelitian Norma \& Hadi (2015) bahwa aktivitas siswa dalam proses pembelajaran dengan model Problem Based Learning (PBL) mengalami peningkatan. Hasil tes belajar diperoleh dari nilai yang didapat siswa setelah mengikuti tes ulangan harian. Analisis hasil tes belajar siswa tiap siklus dapat dilihat pada Tabel 3.

Tabel 2. Aktivitas belajar siswa dengan penerapan PBL

\begin{tabular}{|c|c|c|c|}
\hline \multirow{2}{*}{ No. } & \multirow{2}{*}{ Aspek yang diamati } & \multicolumn{2}{|c|}{ Rerata } \\
\hline & & Siklus 1 & Siklus 2 \\
\hline 1 & $\begin{array}{l}\text { Mengajukan pertanyaan kepada guru atau } \\
\text { siswa lain tentang materi }\end{array}$ & 43,6 & 68,1 \\
\hline 2 & $\begin{array}{l}\text { Menjawab pertanyaan dari guru atau siswa } \\
\text { lain }\end{array}$ & 69,9 & 72,5 \\
\hline 3 & $\begin{array}{l}\text { Mengemukakan pendapat yang sesuai } \\
\text { dengan materi pelajaran }\end{array}$ & 51,9 & 61,2 \\
\hline 4 & Mengisi LKPD secara lengkap & 92,3 & 91,6 \\
\hline 5 & Siswa berdiskusi dalam kelompoknya & 72,4 & 76,9 \\
\hline 6 & $\begin{array}{l}\text { Bersedia mempresentasikan hasil kerja ke } \\
\text { depan kelas }\end{array}$ & 57,1 & 71,4 \\
\hline & Rata-rata & 64,5 & 73,6 \\
\hline
\end{tabular}


Tabel 3. Hasil belajar fisika siswa dengan penerapan PBL

\begin{tabular}{ccccc}
\hline $\begin{array}{c}\text { Penilaian Tes } \\
\text { Ulangan Harian }\end{array}$ & Predikat & $\begin{array}{c}\text { Ulangan } \\
\text { Harian 1 }\end{array}$ & $\begin{array}{c}\text { Ulangan } \\
\text { Harian 2 }\end{array}$ & Keterangan \\
\hline $93-100$ & A & & & \\
$84-92$ & B & 59,0 & 69,3 & Tuntas \\
$75-83$ & C & & & \\
$<75$ & D & 41,0 & 30,7 & Tidak Tuntas \\
\hline
\end{tabular}

Tes hasil belajar diberikan setelah penerapan model Problem Based Learning. KKM yang ditetapkan yakni 75 . Berdasarkan Tabel 3 menunjukkan perolehan tes hasil belajar siswa yang mencapai KKM setiap siklus meningkat, dengan persentese ketuntasan dari 59,0 \% menjadi 69,3\%. Hal ini sesuai dengan kajian terdahulu mengenai penerapan model Problem Based Learning pada proses pembelajaran, yaitu hasil kajian Made (2012) bahwa model pembelajaran Problem Based Learning dapat meningkatkan kemampuan analisis siswa.

Hal ini menunjukkan guru mulai mampu memberikan kesempatan kepada siswa untuk menemukan konsep melalui penerapan model Problem Based Learning (PBL) setelah proses pembelajaran berlangsung. Hasil penelitian Prakoso (2012) menunjukkan aktivitas belajar dan hasil belajar siswa meningkat dengan menerapkan model pembelajaran berbasis masalah. Penelitian ini juga sejalan dengan kajian PTK dari M. Rahmad \& Norazah (2017) yang menerapkan PBL melalui pembelajaran menggunakan web dalam Elektronika Dasar bagi mahasiswa pendidikan fisika, yang hasilnya mampu meningkatkan aktivitas belajar dari siklus I ke siklus II. Oleh karena itu, penerapan $\mathrm{PBL}$ dalam pembelajaran mampu meningkatkan aktivitas dan hasil belajar pada siswa yang diberi tindakan perbaikan pembelajaran.

\section{Kesimpulan dan Saran}

Proses pembelajaran dengan menerapkan model Problem Based Learning (PBL) dapat meningkatkan aktivitas siswa dan hasil belajar siswa di kelas XI MIPA 1 SMA Negeri
12 Pekanbaru pada semester ganjil Tahun Pelajaran 2016/2017 dari siklus I ke siklus II.

Masalah-masalah yang diberikan dalam proses pembelajaran dengan menggunakan model Problem Based Learning, sebaiknya merupakan kejadian atau keadaan nyata dalam kehidupan siswa, agar siswa memahami permasalahan yang diberikan. Bagi peneliti selanjutnya, penerapan model Problem Based Learning tidak dapat digunakan untuk semua materi, disarankan hanya pada materi yang membahas masalah-masalah aktual yang terjadi dalam kehidupan siswa.

\section{Daftar Pustaka}

Arikunto, S., 2009. Penelitian Tindakan Kelas. Bumi Aksara, Jakarta.

Hamalik, Oemar, 2009. Proses Belajar Mengajar. Bumi Aksara, Bandung.

Made Cahyadi Sudarman, Gede, 2012. Penerapan Model Pembelajaran Berbasis Masalah (Problem Based Learning) untuk Meningkatkan Aktivitas dan Hasil Belajar Siswa pada Mata Pelajaran Ekonomi Siswa Kelas X 1 SMA Negeri 1 Sawan, Jurnal Pendidikan dan Pengajaran, UNDIKSHA.

M. Rahmad \& Norazah Mohd Nordin, 2017. Penerapan Pembelajaran PBL berbasis Web untuk Meningkatkan Aktivitas Belajar Elektronika Dasar Mahasiswa Pendidikan Fisika. Prosiding Semirata Bidang MIPA Jambi, No.2 Halaman 1144-1155, 12-14 Mei 2017. ISBN9786025059308. 
Munib, Achmad, 2012. Pengantar Ilmu Pendidikan. UPT UNNES Press, Semarang.

Norma Hidayani, Kurnia \& Hadi, Syamsu, 2015. Peningkatan Kemampuan Analisis Masalah Ekonomi dengan Model Pembelajaran Problem Based Learning (Studi pada Siswa Kelas X IIS 3 SMA 1 Bae Kudus Tahun Ajaran 2014/ 2015), Economic EducationAnalysis Journal, 4 (1).

Prakoso Rubi, Ageng, 2012. Penerapan Model Pembelajaran Berbasis Masalah (Problem Based Learning) untuk Meningkatkan Prestasi Belajar Siswa pada Mata Diklat Praktik Dasar Instalasi Listrik (PDIL) di SMK Muhammadiyah 3 Yogyakarta, Jurnal UNY.
Rusman, 2013. Model-Model Pembelajaran. PT Raja Grapindo Persada, Jakarta.

Sardiman, 2010. Interaksi dan Motivasi Belajar Mengajar. PT Raja Grafindo Persada, Jakarta.

Sudjana, Nana, 2011. Dasar-Dasar Proses Belajar Mengajar. Sinar Baru Algensindo, Bandung.

Sugiyono, 2012. Metode Penelitian dan Pendidikan Pendekatan Kuantitatif, Kualitatif dan $R$ \& D. Alfabeta, Bandung.

Suharto, 2014. Peningkatan Hasil dan Aktivitas Belajar IPS Melalui Model Problem-Based Leaning Berbantuan Media di SMP Negeri 2 Kawunganten Cilacap, Tesis. Program Pascasarjana, Universitas Negeri Yogyakarta. 